\title{
PSYCHE
}

\begin{tabular}{lll}
\hline Vol. 89 & 1982 & No. 3-4 \\
\hline
\end{tabular}

\section{LEPTOTHORAX FABERI N. SP., AN APPARENTLY PARASITIC ANT FROM JASPER NATIONAL PARK, CANADA (HYMENOPTERA: FORMICIDAE)*}

\section{By Alfred BusChinger}

Fachbereich Biologie, Institut für Zoologie, der Technischen Hochschule, D 6100 Darmstadt, Schnittspahnstr. 3 (FRG)

\section{Introduction}

The myrmicine tribe Leptothoracini comprises an astoundingly rich variety of socially parasitic genera and species. Guest ants (Formicoxenus, Leptothorax provancheri), as well as slave-making genera (Harpagoxenus, Chalepoxenus, Epimyrma) and inquilines (Doronomyrmex) have been described (Buschinger, 1981); however, we may suspect that only a minor fraction of the existing species is already known to science. New species can be found nearly everywhere when populations of independent species are closely examined.

In August, 1979, I collected leptothoracine ants in several localities of Jasper National Park, Alberta, Canada. The main object was to find additional material of Doronomyrmex pocahontas, originally described from this locality (Buschinger, 1979). On August 19, when inspecting rotten sticks in the coniferous forest along Mt. Edith Cavill Road near Jasper, I found a colony of a Leptothorax species belonging to the "L. muscorum" group sensu lato. Among the nearly black ants I saw a dealate female which was considerably smaller than the ordinary queens, and more brownish in color. Its general appearance was that of a Leptothorax kutteri queen, an inquiline of $L$. acervorum in Europe (Buschinger, 1965).

* Manuscript received by the editor June 30, 1982 
The colony was kept alive for four subsequent brood periods in artificially shortened annual cycles (Buschinger et al., 1975), and produced (besides alates and workers of the black "muscorum") a total of 56 males, 5 females and 1 worker of the small species. From a second colony that was established with one of the young females, I got an additional 4 males, 2 females, and one worker. This new, apparently parasitic species will now be described.

\section{Description of Leptothorax faberi $\mathrm{n}$. sp. Figs. 1-5}

Holotype female: total length $3.45 \mathrm{~mm}$, head length 0.67 (excluding mandibles), head width 0.59 (behind eyes), scape length 0.49 , greatest diameter of eye 0.16 , thorax length 0.98 , thorax width 0.58 , length of petiole in lateral view 0.27 , width of petiole 0.22 , length of postpetiole 0.20 , width of postpetiole 0.32 , length of forewing 2.89 , hind wing 1.90 , length of hind femur 0.58 , hind tibia 0.46 . The end of the gaster is somewhat curved down so that its length $(1.3 \mathrm{~mm})$ cannot be determined with precision.

Paratype females (selected measures of two females): total length $3.2 / 3.47 \mathrm{~mm}$, head length $0.68 / 0.79 \mathrm{~mm}$, thorax length $0.97 / 1.18$ $\mathrm{mm}$, thorax width $0.50 / 0.66 \mathrm{~mm}$.

Habitus in general similar to the queens of the genus Leptothorax, subgenus Leptothorax sensu Smith (1950) (= Mychothorax Ruzsky). Mandibles with 5 or 6 teeth of normal size; one or two tiny teeth may be present between the normal ones in the middle of the masticatory border. Maxillary palps 5-segmented, labial palps 3-segmented. Antennae 11-jointed with a 3-jointed club. Anterior border of clypeus with a feeble notch (fig. 1a). Three ocelli present. Thorax (fig. 1b) as in Leptothorax muscorum. Epinotal spines of moderate size, acute; epinotal spine index (Buschinger, 1966) between 1.5 and 1.8. Wings as in L. muscorum (fig. 2). Petiole (fig. 1 b) not pedunculated; viewed from above, the outline is nearly quadrate, with a slight convexity of the sides. In lateral view the anterior face is slightly concave, the posterior face distinctly so. The summit is flat, descending backward and forming a right angle with the anterior face, and an obtuse angle with the posterior one. A conspicuous ventral spine forms the anterior end of a ventral, concave, triangular field, the sharp, ventrolateral edges of which diverge towards the postpetiole. 

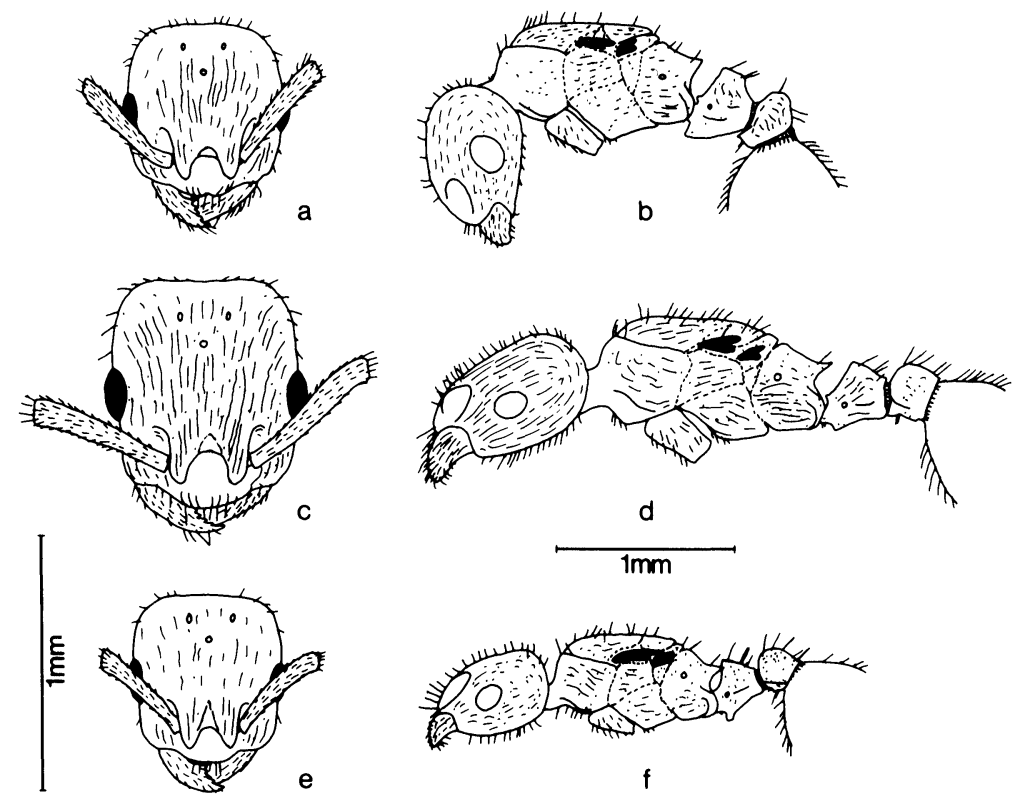

Fig. 1. Head in front view, and head, thorax, and petioles in lateral view of females of Leptothorax. a,b, L. faberi $\mathrm{n}$. sp.; c,d, its host species, "L. muscorum", large black form; e, f, "L. muscorum", small brown form, for comparison.

Postpetiole (fig. $1 \mathrm{~b}$ ) from above about 1.4 times broader than the petiole, kidney-shaped with a slight anterior concavity. In lateral view, the anterior face is slightly convex, nearly perpendicular. Summit rounded, posterior face slightly concave, descending towards the gaster.

The seemingly distinct ventral spine is formed by a sickle-shaped, transverse protuberance with a sharp anterior edge.

Head, thorax, petiole, and postpetiole mostly coarse and rugulose, gaster smooth and shining. Body sparsely covered with erect, short and stiff hairs; legs and antennal scapes with abundant, appressed hairs; funiculus with dense, suberect hairs. Maximal length of hairs in head, thorax and gaster $0.06-0.08 \mathrm{~mm}$.

Coloration: yellowish-brown with head, dorsal parts of thorax, petiole, postpetiole and gaster somewhat darker brown. Legs uniformly brown, antennae brown with a blackish-brown club. 
One alate female was dissected. She had 6 ovarioles, a comparatively large poison gland, a Dufour's gland of ordinary size for most independent Leptothorax species, and an empty receptable also of ordinary size and shape.

Allotype male: total length $3.44 \mathrm{~mm}$, head length 0.63 (excluding mandibles), head width 0.65 (behind eyes), scape length 0.26 , greatest diameter of eye 0.28 , thorax length 1.21 , width 0.70 , length of petiole 0.32 , width 0.25 , length of postpetiole 0.24 , width 0.29 , length of forewing 3.09 , hind wing 2.04 , length of hind femur 0.79 , hind tibia 0.55 , length of gaster ca. $1.05 \mathrm{~mm}$. Paratype males (selected measures of two males): total length $3.46 / 3.58 \mathrm{~mm}$, head length $0.60 / 0.65 \mathrm{~mm}$, thorax length $1.22 / 1.28 \mathrm{~mm}$, thorax width $0.67 / 0.70 \mathrm{~mm}$. Habitus in general like that of other males of the subgenus Leptothorax. Mandibles without teeth, masticatory border rounded or straight. Maxillary palps 5-segmented, labial palps 3-segmented. Antennae 12-jointed, without club. Clypeus prominent, vaulted, its anterior border straight. Eyes and the ocelli as large as usual for the subgenus Leptothorax.

Thorax with Mayrian furrows. Epinotum without distinct spines, but their place marked by two low ridges (fig. 3).

Petiole not pedunculated, with nearly straight anterior and posterior faces of the rounded node. A small ventral spine is present, with two diverging ventrolateral edges, as in the female. Postpetiole similar to that of the female, except that the anterior face is less steep and more convex, and the ventral spine or transverse edge is smaller (fig. 3).

Male genitalia: see fig. 3 .

Head, sides of pronotum and of petiole coarse, dorsal and extended lateral parts of thorax, node of petiole, postpetiole and gaster smooth and shining. Body moderately covered with tapering, curved hairs of variable length, in the thorax reaching $0.10 \mathrm{~mm}$, on the petiolar node $0.14 \mathrm{~mm}$. Head and particularly the mandibles with abundant, long, tapering hairs. Antennae and legs with abundant, appressed or suberect hairs.

Coloration: whole body black or blackish-brown with the scutellum, the metanotum, sometimes the pronotum, the mandibles and legs somewhat lighter brown. In most males the scutellum differs so markedly in coloration from the surrounding parts of the thorax that this was the most valuable character for identifying the new species' males when they were still alive in the nest. 

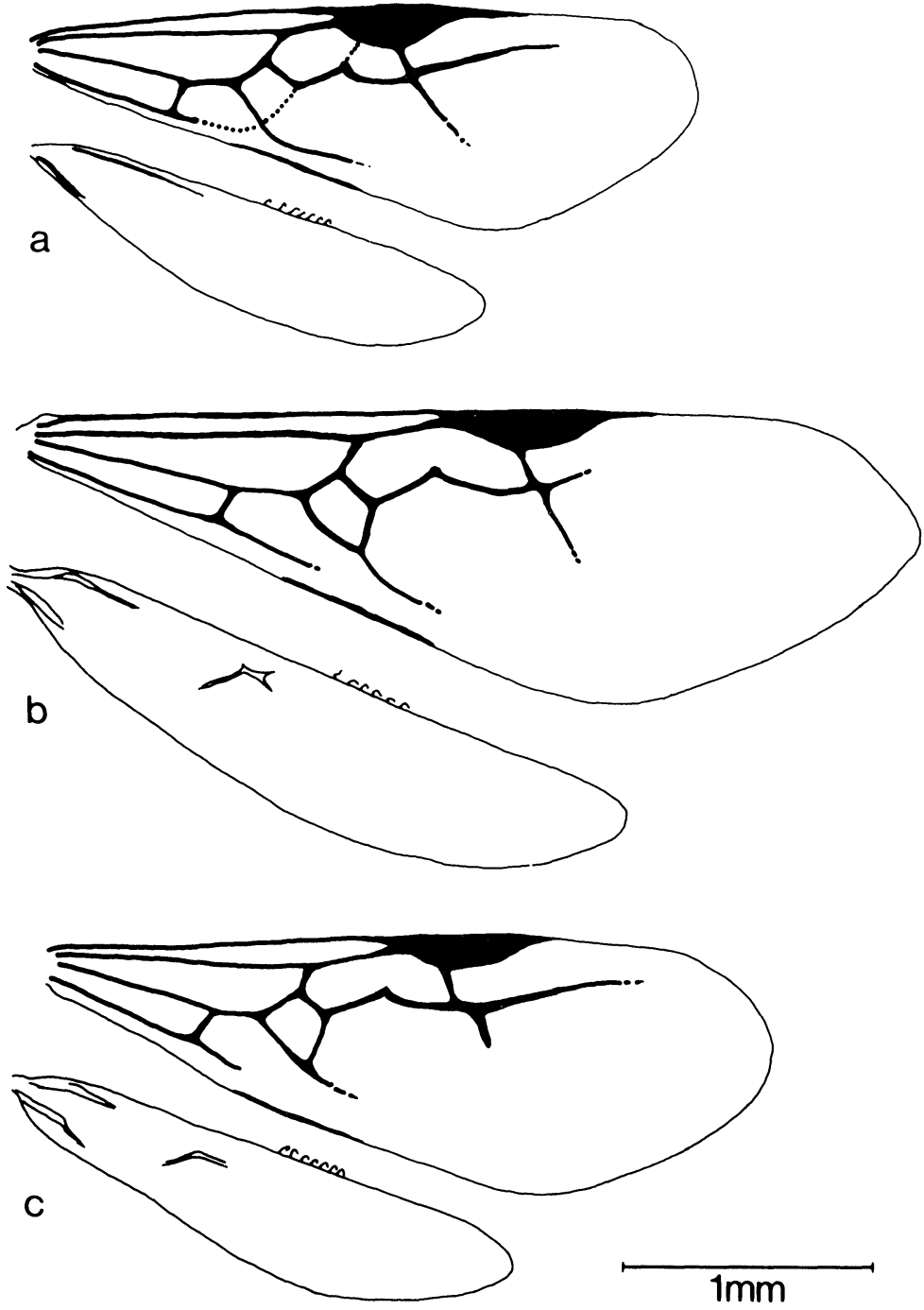

Fig. 2. Wings of females of Leptothorax. a, L. faberi n.sp.; b, "L. muscorum", large black form; c, "L. muscorum", small brown form. The dotted lines in the $L$. faberi fore wing (a) indicate veins that are present in the left, and absent in the right wing of the same specimen. Wing venation is variable in all species of this group. 


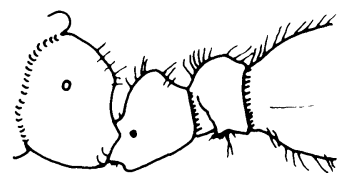

a
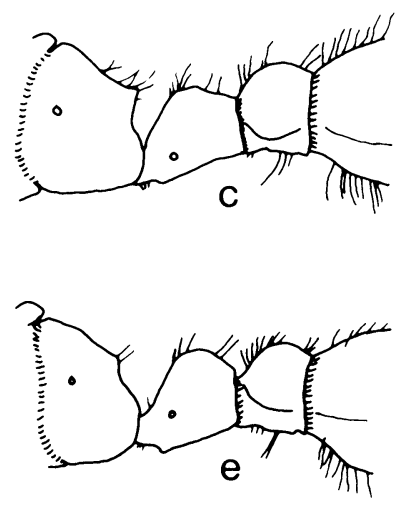

$1 \mathrm{~mm}$
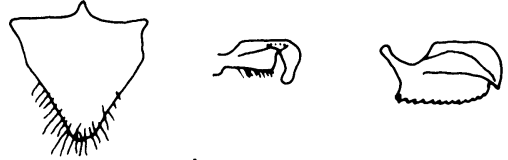

b
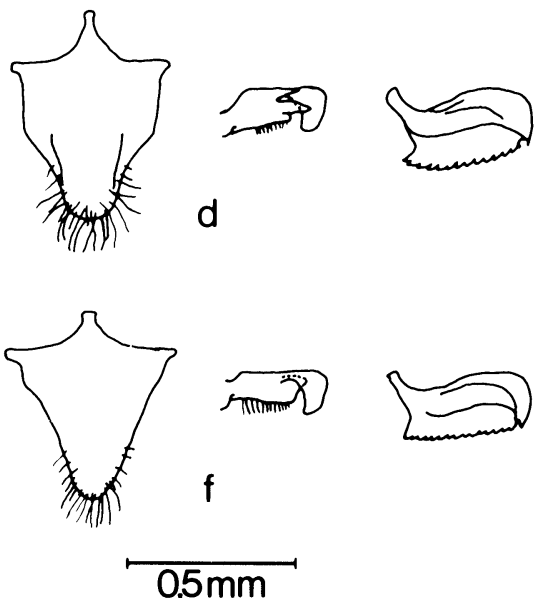

Fig. 3. Epinotum and petioles of males, and male genitalia (subgenital plate, volsella with lacinia, and sagitta) of Leptothorax. a,b, L. faberi n.sp.; c,d, its host species, "L. muscorum", large black form; e,f, "L. muscorum", small brown form. The shapes of the sagitta and volsella with lacinia vary considerably in all 3 species.

Allotype worker: total length $3.02 \mathrm{~mm}$, head length 0.66 (excluding mandibles), head width 0.58 , scape length 0.46 , greatest diameter of eye 0.16 , thorax length 0.91 , width 0.43 , length of petiole 0.24 , width 0.20 , length of postpetiole 0.17 , width 0.30 , length of hind femur 0.51 , hind tibia 0.42 , length of gaster approximately $1.05 \mathrm{~mm}$.

Habitus similar to an ordinary worker of L. muscorum, but somewhat more stout and clumsy (fig. 4). Mandibles with 6-7 teeth, palps with 5 and 3 joints, as in the female. Eyes of moderate size, ocelli absent, anterior border of clypeus with a notch as in the female. Thorax with a deep meso-epinotal suture, and the promesonotal suture clearly visible. Pronotum comparatively wide. Epinotal spines as in the female, epinotal spine index 1.6. Petiole and postpetiole as in the female, as well as the appendages. Head and whole body coarse and rugulose except for the gaster, which is 

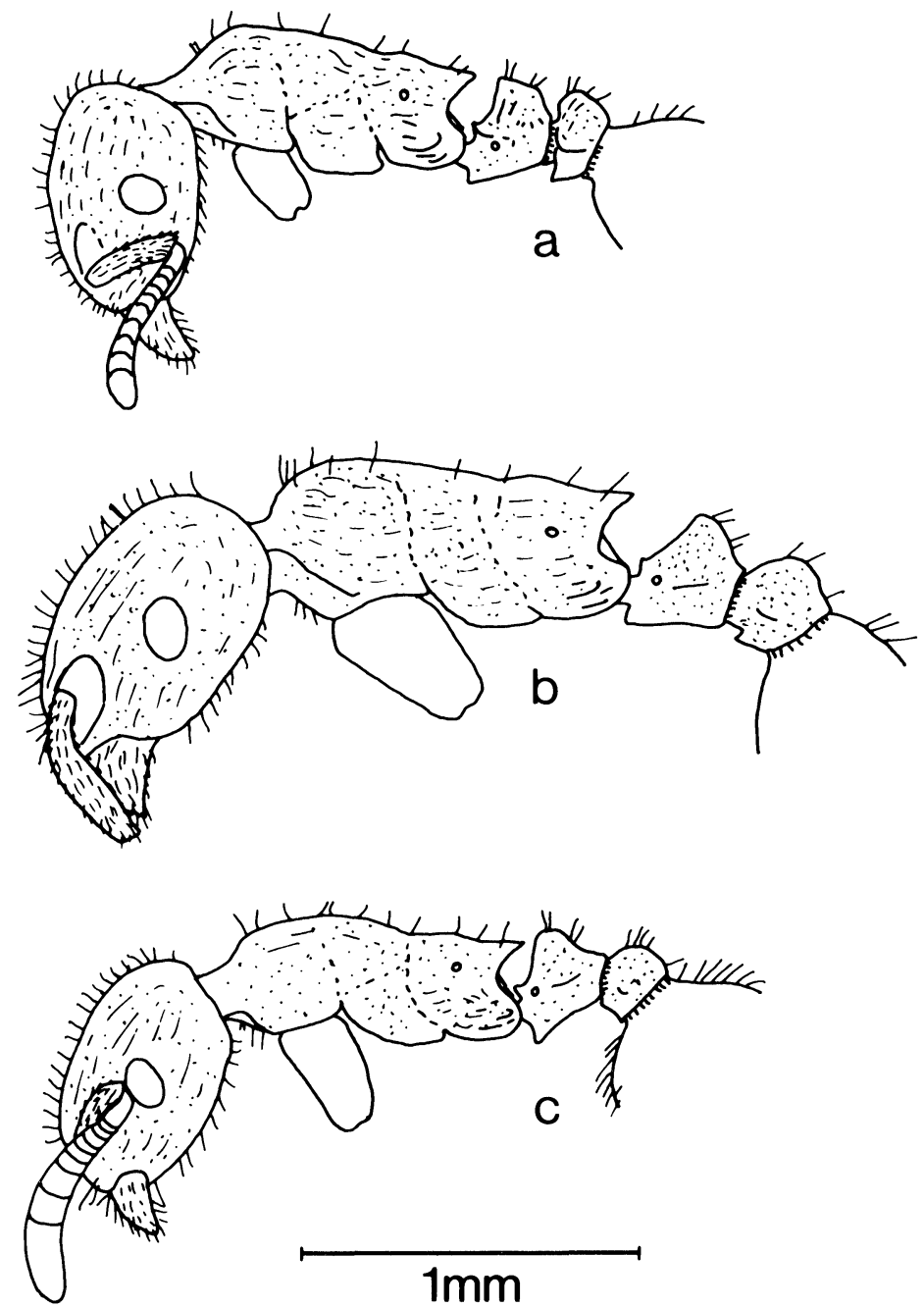

Fig. 4. Head, thorax, and petioles of workers in lateral view. a, L. faberi n.sp.; b, its host species, "L. muscorum", large black form; c, "L. muscorum", small brown form, for comparison. 
smooth and shining. Pilosity as in the female. Coloration yellowishbrown with the head, the antennal club and the gastral tergites darker brown.

The karyotype (fig. 5) was determined from 8 male pupae, following the method of Imai et al. (1977). In 68 metaphase plates a haploid number of 15 chromosomes was found, 13 of which are metacentric or submetacentric and two are subtelocentric. The second-largest chromosome exhibits a very characteristic banding. In 7 metaphase plates one additional, subtelocentric chromosome was found; this, however, may be an artefact. The host species, on the contrary, has a haploid chromosome number of 17 as does the second, smaller "L. muscorum" from Jasper Park, and as occurs in European L. muscorum.

Type locality: Jasper National Park, Alberta, Canada, a few meters above the road from $93 \mathrm{~A}$ to $\mathrm{Mt}$. Edith Cavill parking lot, in about $1500 \mathrm{~m}$ elevation. Numerous nests of the host species and also of a smaller kind of "L. muscorum" were found inhabiting the rotten sticks and logs lying on the ground of a rather open coniferous forest.

Derivatio nominis: The ant is dedicated to my late friend, Dr. Walther Faber, from Vienna, Austria, whom I admired for his excellent studies in social parasitic ants.

Differential diagnosis: The new species closely resembles the European inquiline ant Leptothorax kutteri, particularly with respect to size, coloration, and the ventral spines in petiole and postpetiole. It differs from that species through the lack of erect hairs in the antennal scapes and the tibiae. Also, the characteristic sculpture of the head of L. kutteri females is absent in L. faberi. The remarkable light coloration of the male's scutellum and metanotum is, as far as I know, unique among leptothoracines belonging to the subgenus Leptothorax and their social parasites.

The host species (fig. 1) and L. faberi are easily distinguished by the latter's smaller size and lighter coloration (female). They also differ with respect to the karyotypes. $L$. faberi could only be confused with the second, smaller Leptothorax "muscorum" form in Jasper Park (fig. 1), which is the host species of Doronomyrmex pocahontas. However, this species differs in the shape of petiole and postpetiole from L. faberi, and it has a karyotype which is identical to that of the large, black L. "muscorum", host species of L. faberi. 


\section{Sictitiogento \\ Gic

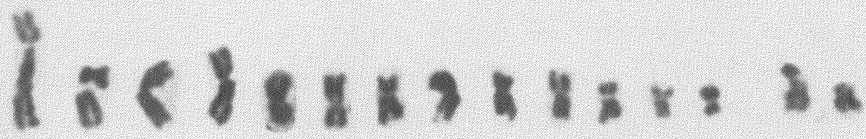

Fig. 5. Karyotype of Leptothorax faberi $\mathrm{n}$.sp. The normal karyotype has $\mathrm{n}=15$ chromosomes, but 2 of 18 individuals had $n=16$ in 2 out of 25 and 5 out of 18 metaphase plates respectively (center line).

\section{Biological observations}

All observations were made under laboratory conditions, and, due to the restricted material, they must be fragmentary. However, a few interesting facts could be recorded, particularly with respect to reproductive behavior. Sexuals of $L$. faberi were observed to leave the nest and to become sexually active in the morning, about 3 to 4 hours after the morning rise in temperature in our artificial $15 / 25^{\circ} \mathrm{C}$ temperature rhythm. Copulation was seen twice, the behavior being identical to that of Leptothorax kutteri, Doronomyrmex pacis and other social parasites of this group (Buschinger, 1971, 1974, 1975). A distinct sexual-calling behavior, resembling that of L. kutteri, was not seen, but poison gland secretion seems to serve as sexual pheromone as in the species mentioned above. The poison gland of one female was squeezed onto a small piece of filter paper, and the paper then put into a nest with $L$. faberi males. The males suddenly became excited, and a few began to mount the host species workers. 
Mounting attempts of males on L. faberi females could also be released by gently squeezing a female within a swarming cage with males flying and crawling around.

One mated and dealate female was placed into a nest of the host species; however, it had to be removed quickly because it was seriously attacked by the workers. This same female then was put together with two workers from the mother colony, and with a few larvae from another host species colony, into an artificial nest. The faberi queen became fertile, and after a hibernation I increased her host worker stock using 25 worker pupae of Leptothorax acervorum. I used $L$. acervorum pupae because the normal host species colonies did not produce sufficient worker pupae: $L$. acervorum is an ideal "replacement host species" for several parasitic species. Thus, we succeeded in breeding Formicoxenus nitidulus, guest ant of Formica, with L. acervorum (Buschinger, 1976). After a second hibernation the original host species workers were dead, and the colony produced $1 \mathrm{~L}$. faberi male. Further acervorum worker pupae were added, and in the third artificial brood period a total of 4 faberi males, 2 females, and 1 worker was produced. During this period the faberi queen died.

The second laboratory-mated faberi queen was placed into the mother colony, where it was accepted, apparently became fertile, and survived for two artificial annual cycles alongside its mother queen. Both died at the end of the third laboratory brood period of this colony.

The host species of $L$. faberi is a comparatively large, nearly black form which is related to $L$. muscorum Nyl., but it differs markedly from this European species. I cannot identify this form yet. A second, smaller species with more brownish coloration occurs sympatrically with the black form in Jasper Park. This smaller " $L$. muscorum" is the host species of Doronomyrmex pocahontas (Buschinger, 1979). It looks more similar to L. muscorum from Europe than to North American specimens, but it seems also to represent a distinct species. Besides the morphological differences of size and coloration, the two Canadian "muscorum" also differ markedly with respect to their sexual behavior. The "small brown" species' females exhibit a characteristic sexual calling behavior (Locksterzeln) similar to European L. muscorum Nyl. and most social parasites of this group. I was able to breed this species over several generations in the laboratory. The "large black" species on 
the contrary, seems to make a mating flight. As with European $L$. acervorum, I could never induce mating in any kind of flight cage in the laboratory.

\section{Discussion}

The biology of Leptothorax faberi deserves to be discussed with respect to several features.

First of all, I am fairly convinced that this species represents an obligatorily parasitic ant. It seems unreasonable to assume that the one queen originally found should have run into the "muscorum" nest by chance during collecting, that it would have been accepted there, and that it could reproduce within the foreign nest. The very low number of only two workers produced in two colonies is another datum in favor of the opinion that $L$. faberi is a parasitic ant.

Finally, the presence of a postpetiolar ventral spine also supports this hypothesis, since most parasitic species among the Leptothoracini have it.

The production of host species sexuals within the parasitized colony even in its third laboratory brood period indicates that a host species queen must have been present. This was not checked by dissection, but several dealate host species females were living in the nest when it was collected. Thus, $L$. faberi seems to live as an inquiline ant alongside the fertile host colony queen(s), as do Doronomyrmex pacis, Leptothorax goesswaldi, L. kutteri, and others. Inquilines, however, are usually workerless. In Doronomyrmex pacis and Leptothorax kutteri, the worker caste is completely lacking in the vast majority of all the colonies we ever collected or kept in the laboratory, this being several dozen of D. pacis and about 100 of L. kutteri. However, a total of 2 or 3 workers of both species have been produced in laboratory culture, and one L. kutteri worker was found in a field colony (Brückner, in litt.). At present, it is impossible to decide whether the two L. faberi workers represent such rare exceptions, or whether the species usually will produce some more workers.

I also doubt that the exceptionally high ratio of males/females in the offspring of $L$. faberi represents the natural condition. Additional material must be collected in the field to clarify these problems. 
With respect to systematic relationships, the new species clearly supports "Emery's rule," under which socially parasitic ants are always closely related to their respective host species group. No characters linking L. faberi with European Doronomyrmex pacis or Leptothorax kutteri could be found. The new species shares a characteristic structure in the petiole with the host species and with Doronomyrmex pocahontas. The Canadian species have two distinct small teeth at the base of the anterior face of the petiole just above its articulation with the epinotum (fig. 1). These teeth are lacking in their European relatives.

The holotype female, 2 allotype males and 1 worker, and voucher specimens of the host species are deposited in the Museum of Comparative Zoology, Harvard University, Cambridge, Mass. (no. 32758).

\section{Summary}

Male, female and worker of an apparently parasitic ant, Leptothorax faberi $\mathrm{n}$. sp., are described. The new ant species was found in a queenright colony of Leptothorax muscorum (sensu lato) in Jasper National Park, Canada. It differs from the host species in its smaller size, in the shape of the petioles (figs. 1, 3, 4), in sculpture and coloration. The karyotype with a haploid number of 15 chromosomes (fig. 5) is also different from that of the host species, which has $\mathrm{n}=17$ chromosomes. Very few workers have been raised in two laboratory colonies. Thus, $L$. faberi seems to represent an inquiline species.

\section{Acknowledgments}

I am grateful to my student, Karl Fischer, who assisted me during the collecting trip, and who also carried out the karyotype studies. I also thank the Jasper Park authorities for having tolerated our collecting activities. I am indebted to R. H. Crozier for critically reading the English text.

\section{References Cited}

BUSCHINGER, A.

1965. Leptothorax (Mychothorax) kutteri $\mathrm{n}$. sp., eine sozialparasitische Ameise (Hymenoptera, Formicidae). Ins. soc. 12: 327-334. 
1971. "Locksterzeln" und Kopula der sozialparasitischen Ameise Leptothorax kutteri Buschinger (Hym., Form.). Zool. Anz. 186: 242-248.

1974. Zur Biologie der sozialparasitischen Ameise Leptothorax goesswaldi Kutter (Hym., Formicidae). Ins. soc. 21: 133-144.

1975. Sexual pheromones in ants. In Pheromones and Defensive Secretions in Social Insects. Proc. Symp. IUSSI Dijon 1975, pp. 225-233.

1976. Eine Methode zur Zucht der Gastameise Formicoxenus nitidulus (Nyl.) mit Leptothorax acervorum (Fabr.) als "Wirtsameise" (Hym., Form.). Ins. soc. 23: 205-214.

1979. Doronomyrmex pocahontas $\mathrm{n}$. $\mathrm{sp}$., a parasitic ant from Alberta, Canada (Hym., Formicidae). Ins. soc. 26: 216-222.

1981. Biological and systematic relationships of social parasitic Leptothoracini from Europe and North America. In Biosystematics of Social Insects, ed. P. E. Howse and J.-L. Clément (Academic Press, London, 1981), pp. 211-222.

Buschinger, A., Frenz, G. UNd M. Wunderlich

1975. Untersuchungen zur Geschlechtstierproduktion der dulotischen Ameise Harpagoxenus sublaevis (Nyl.) (Hym., Formicidae). Ins. soc. 22: 169-182.

Imai, H. T., Crozier R. H., AND R. W. TAYloR

1977. Karyotype evolution in Australian ants. Chromosoma 59: 341-393.

Sмiтh, M. R.

1950. On the status of Leptothorax Mayr and some of its subgenera. Psyche 57: 29-30. 

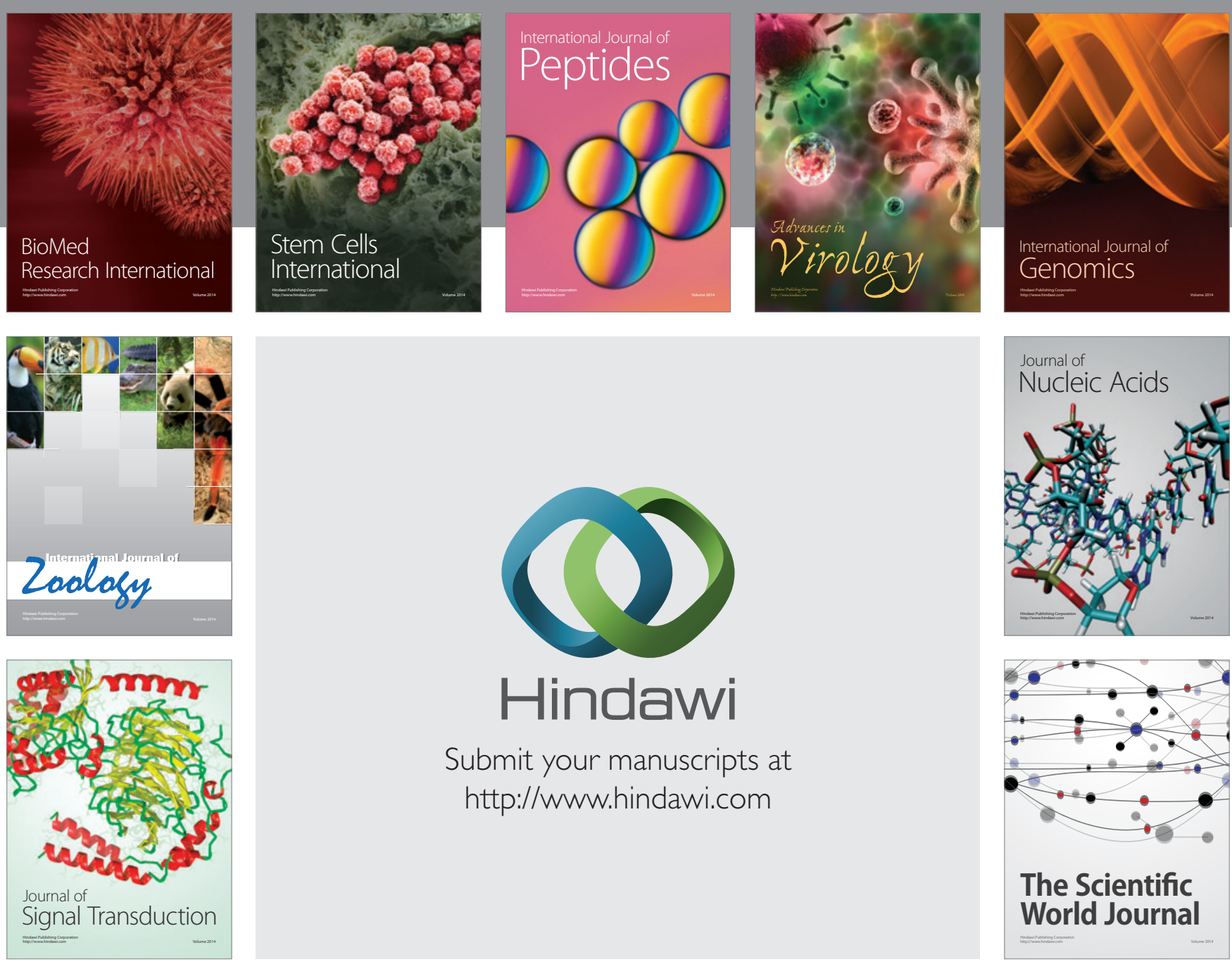

Submit your manuscripts at

http://www.hindawi.com
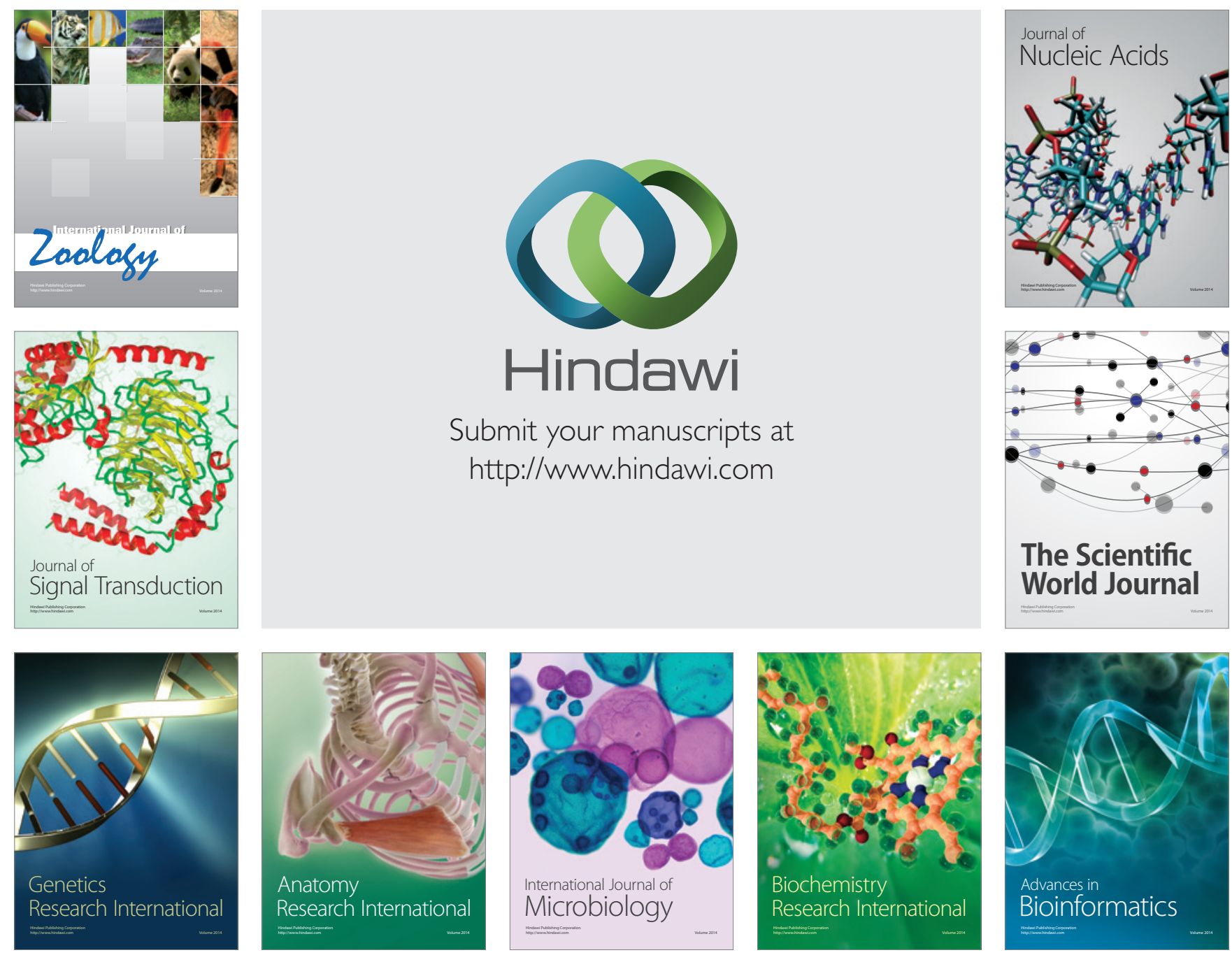

The Scientific World Journal
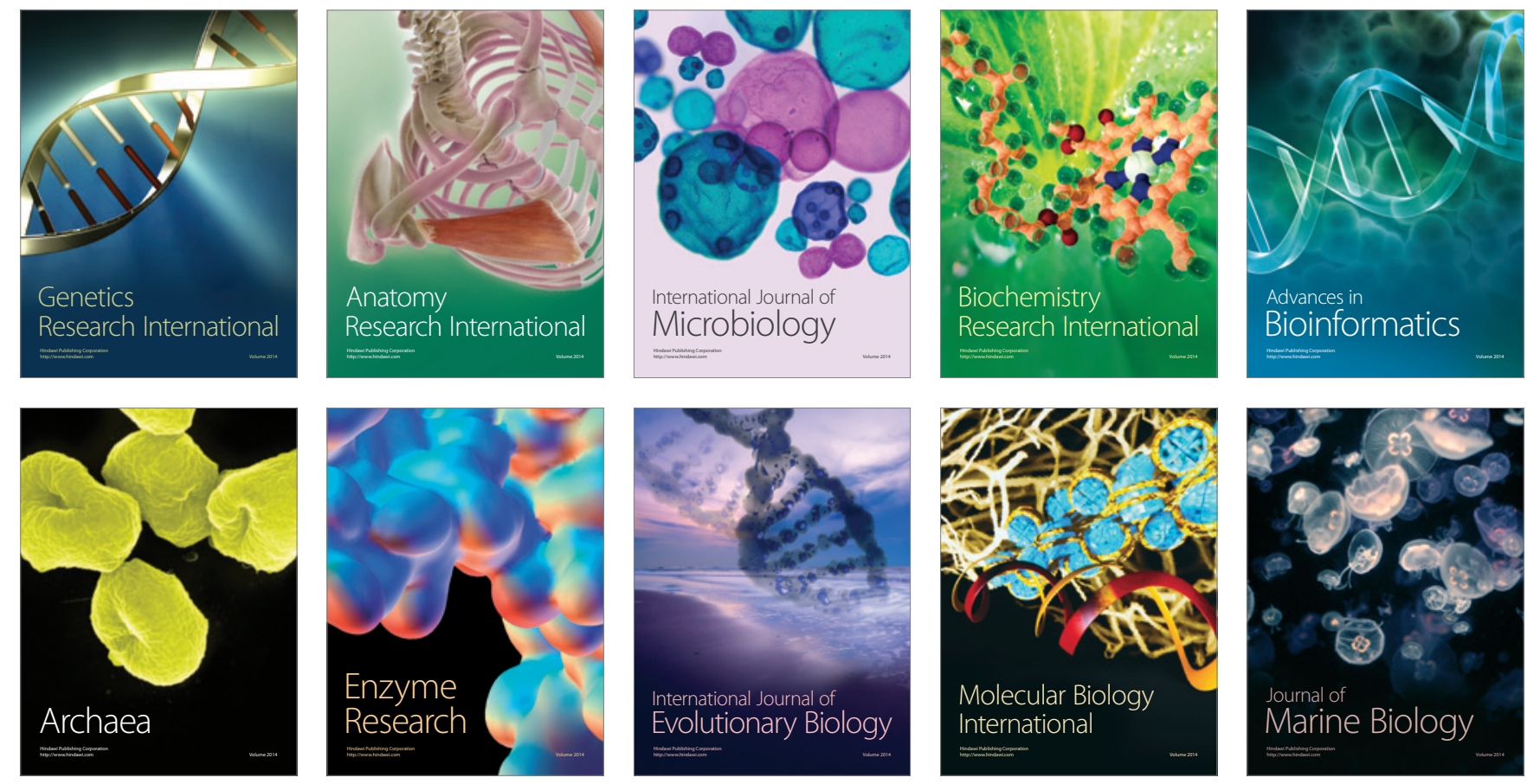